\title{
Shaping New Forms of Citizenry through Community Co-Creation and Participatory Design Processes
}

\author{
SHANNON CRISS \\ University of Kansas
}

\begin{abstract}
Much of what we consider to be architecture practice responds primarily to a client's specific needs in relation to a particular, bounded site. Clients often present architects with a site, a design challenge, a limited budget and scope of work. The project is typically guided by engaging with the client through a contracted relationship. The traditional course is for the architect to begin making pre-design decisions about site orientation, program needs, and aesthetics. After that, the progression moves from schematic and conceptual designs to more developed designs, ultimately resulting in a set of construction documents that serve as a limited contract. This relationship is largely governed by professional practice standards through the American Institute of Architects (AIA), where expectations, risks and liability of the architect are limited and managed. The difficulty in this linear and narrowly defined engagement is that these processes are inherently technical as a way to navigate restrictive time, budgets and design intentions. While an architect's responses to design challenges are often adaptive as related to form making, a framework that is strictly client-centered prevents greater consideration of the needs and desires of the larger community. A new call for how we educate students is needed, one that expands the role of practice to meet the needs of public interest.
\end{abstract}

\section{TOWARDS A PRACTICE OF ADAPTIVE DESIGN}

As architects move towards a more adaptive design paradigm that concerns itself with issues of social impact, there are limitations to appropriate processes and frameworks to move through on the path towards a substantial resolution of the design challenge. The basic progression of schematic design, design development, construction documents, and contract administration is not formatted properly to deal with more ambiguous design challenges such as establishing community-centered coalitions, advocating for social equity, and responding to the needs of the community. For this reason, many architects that engage in social impact design as professionals or as part of a firm are often limited in their ability to be effective advocates. Rather than meeting communities where they are, architects often attempt to frame their relationship in limited ways, budgeting their time with communities in need of social impact design services as they would with a client. The evolution of an architect's role and responsibility is nonetheless limited by a paradigm that is client-centered, and therefore unable to adapt to design challenges where the community is the client, and the design services rendered are for the public good.

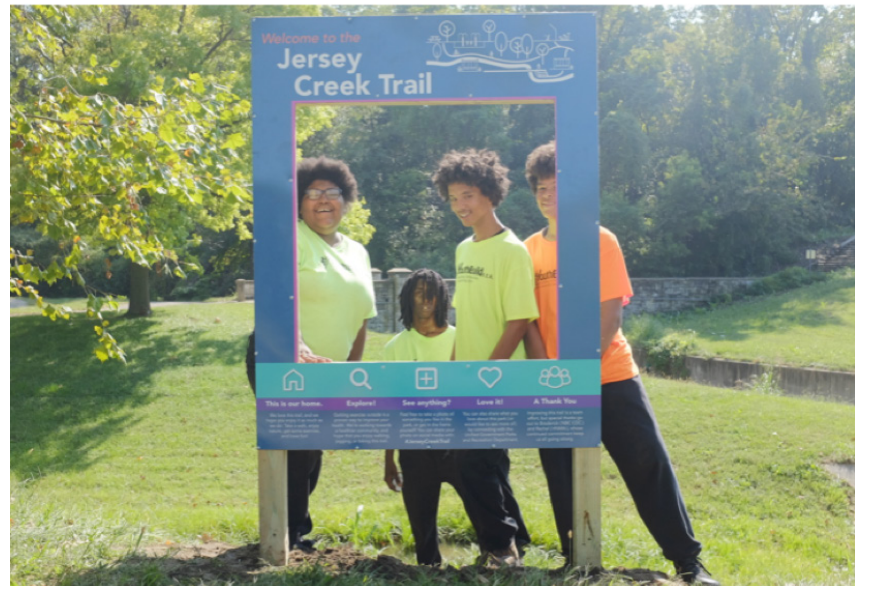

YouthBuild highschool students collaborate with the installation of park elements that are intended to promote new conversations about the park and its potential new uses.

In response to the limitations presented by taking a clientcentered approach, human-centered design principles have emerged out of the Stanford D-School and IDEO. Founder David Kelley "doesn't consider IDEO to be experts in any specific industry." IDEO's main tenet is developing empathy for the end-user of their projects and that the purpose is to figure out what humans want by doing two things: 1) try to understand people through observing them and 2) attempt to understand what the user experience is like, or feel what the user feels. ${ }^{2}$ This process asks designers listen to (co)create a proposal that has a positive impact within the community, ultimately evolving the design to deliver a completed proposal to the community stakeholders. By framing their design solutions through the lenses of others, staying connected to the behaviors and needs of the people they are designing for, an alternative model of practice, one will emerge that is more suitable navigating adaptive design challenges. This filter allows for a more flexible approach than the traditional architectural model, where the desire of the community is given primary consideration. Kelley says "(s)ometimes the best ideas are so obviously staring us in the face that we miss them. We can't see them because we're looking at things from the outside in, instead of looking at things through the eyes of the end-user." ${ }^{\prime 3}$

\section{CO- CREATING IN SPACES OF POVERTY}

The roots of social problems run deep under the surface of a place, time and a culture. Within communities, good health results from the interplay of many factors where only some of which are within an individual's control. "More than one-half 
of what determines a person's health outcomes results from influences in the social and built environments." ${ }^{\prime \prime}$ There is an uneven distribution of health outcomes across the country that are demonstrated through a high degree between geographic overlap between poor health outcomes and neighborhoods with limited resources. These are commonly referred to as the Social Determinants of Health. "Historical maps and documents provide evidence of long-term neighborhood disinvestment rooted in discriminatory housing policy, spanning decades. Not surprisingly, these historically disinvested neighborhoods are the same areas that today experience the worst health outcomes." ${ }^{5}$

As in most American cities in the 1930's, working in a nearby community, residents of Kansas City, Kansas suffered great economic loss during the Great Depression. Home foreclosures were common at that time and as a result the federal government created the Home Owner's Loan Corporation (HOLC). ${ }^{6}$ HOLC developed an assessment process whereby assessors evaluated neighborhoods and rated them in an increasing order of their insurance risk. Maps were developed with a four-scale rating, the highest risk was "redlined" and considered "hazardous."

These redlined zones most commonly represented the highest percentage of "Blacks in the neighborhood, singling out the presence of Blacks in a neighborhood as particularly harmful to property values and the overall likelihood for loan repayment." The resulting impact of these assessments about the people who lived in the homes to be refinanced-or in the case of "red-lined" neighborhoods, not being refinancedwas devastating. These evidences can be physically seen in many neighborhoods today with deteriorating and removed homes, poorly maintained infrastructure (street lighting, sidewalks, landscaping, storm water collection, etc.) and deteriorating public parks with little amenities. The impacts are palpable in the built environment. The capacity of citizens to re-create or co-create the future of their communities was and still remains limited.

\section{SPATIAL AGENCY}

So, how can an architect begin to address these spaces of disinvestment? In Spatial Agency: Other Ways of Doing Architecture, the authors Awan, Schneider and Till identify the phrase Spatial Agency: "Spatial does not so much replace architectural as a term, but radically expands it...social space explicitly acknowledges the contribution of others, and with this dismisses the notion of expert authorship that the professions still cling to. ${ }^{\text {" }}$ Social space is charged with the dynamics of power and empowerment and embodied with a future social relationship, "not merely as a harbinger of aesthetics or as an instruction to a contractor." Spatial agency constitutes sites of action where the work emerges in social interactions, where "boundaries shift from within; boundaries are very tricky. What boundaries provisionally contain

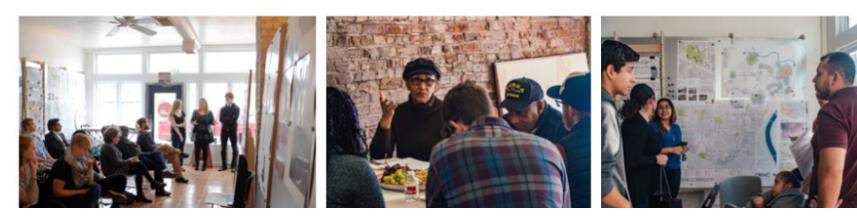

Students meet with community partners in our satellite design center to gather their insight and provide feedback on sftudents' findings.

remains generative, productive of meanings and bodies." ${ }^{\prime 10}$ This way of working is shaped and reshaped by a network of social interactions and relationships where boundaries and spaces are under constant negotiation and deeply contextual. Rather than shaping a building, the focus is on the processes that connect the production of the built environment. The environment is complex and contingent to the capacity of our community partners to collaborate and explore the possibilities of space in which they currently inhabit.

\section{COLLABORATIVE APPROACH}

"Increasingly, people across the globe are engaging in improving the urban environments they live in. They act in response to urgent issues and compelling needs such as shelter, security, employment, health and education. Community-based initiatives indicate the ability of citizens to present solutions to challenges posed by everyday life, and use creativity to transform and multiply existing resources. Inadvertently political by nature, these initiatives are a response to the incapability of today's cities to cope with urban challenges via traditional planning culture and its instruments. They invite different actors to cooperate towards a new urban scheme driven by participation and a proactive attitude. They build collective space, collectively. They reveal a shared layer of the city that is complex, incremental and difficult to articulate, as it does not organize systems, but rather operates on a local level fulfilling micro-agendas through direct action." ${ }^{\prime 1}$

Our unique position as both educators and practitioners allow us to move between these two roles in community spaces where we prioritize the interests and priorities of everyday people seeking co-created solutions to spatial problems. Instead of creating spaces where the citizen is passive, we create spaces of engagement where notions of inclusion, authorship and decision-making bring the spatial agent and user closer to level playing fields.

\section{MOBILIZING THE COMMUNITY THROUGH ENGAGEMENT}

By not emphasizing the physical aspects of space, but rather on addressing the social (spatial) relations through mobilizing social networks, community engagement is possible. Henri Lefebvre writes " $(w)$ hen no heed is paid to the relations that inhere in social facts, knowledge misses its target; our understanding is reduced to a confirmation of the undefined and indefinable multiplicity of things, and gets lost in classifications, descriptions and segmentations." ${ }^{12}$ Attention to 

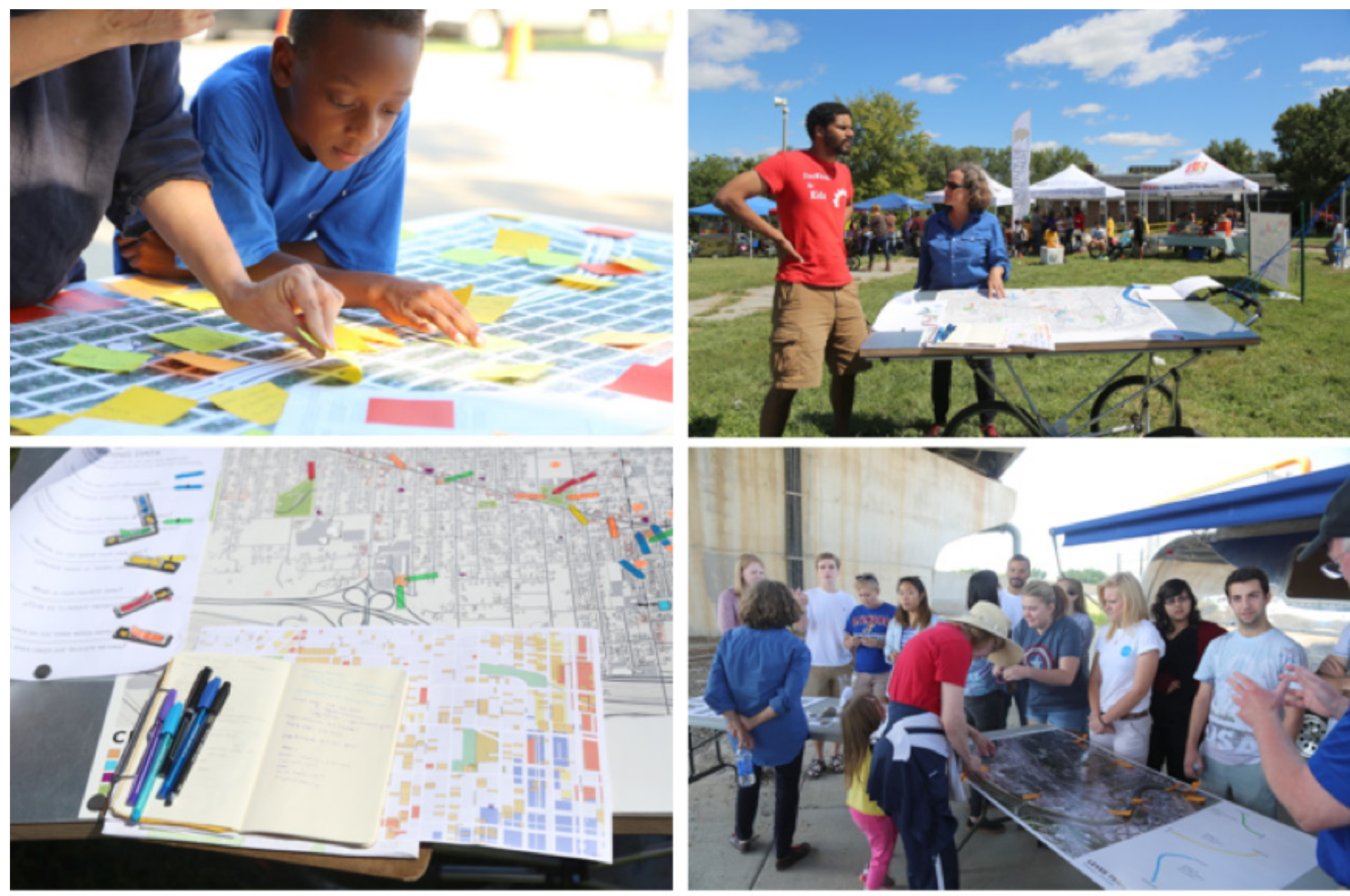

Students and faculty engage community members through the KJ Method at various community events.

existing and recognized social structures is essential to the creation of spaces that have more relevance to those who use and live in them. In order to effectively engage and mobilize the community, we identified three community engagement methods that have proven effective: 1.) the KJ Method, 2.) Participatory Budgeting and 3.) Photovoice. The following reveals principles learned:

The KJ Method is named after Kawakita, Jiro, a Japanese anthropologist, and was created in the 1960's. It is a consensus-building exercise that helps community members organize a complicated range of ideas. ${ }^{13}$ It can be an effective way for individuals to externalize information that they are independently considering through an open and organized way of prioritizing data. Through this process, group consensus can be fostered. This method, in opposition to traditional meetings, it is challenging to have enough time for a problem to be described and understood as a result of limited meeting formats. The KJ Method focuses the team on one question, then instantly sets everyone to work on the same task simultaneously. The benefits are that it is silent, where everyone in the group is provided with blank 'sticky notes' and markers, setting everyone involved in a process of brainstorming where insights and opinions are considered independently.

Another benefit is that it makes effective use of time, in contrast to traditional meetings where only one person can speak or visually communicate on the white board at one time. With the KJ Method, all of the sticky notes are posted simultaneously where opportunities for holistic assessments of the problem space helps everyone understand that it is not single opinion versus another, but rather how multiple opinions are possible. And finally, this method promises equal representation, where politics and personalities are not prioritized. It matters less who has the most power or eloquent argument, but rather a framework where all involved works silently together as a collective team, where decisions are made democratically and there is little space for coercion. Within a fairly short amount of time, the independent thoughts can be organized into diagrams where the visual representation of a team's observations, knowledge, concerns and ideas are organized. It is a powerful way for teams to come together, solve problems, reach consensus and jointly make priorities to take next steps.

The first full Participatory Budgeting process was developed in 1989 in the Brazilian City of Porto Alegre by the Brazilian Workers' Party for its municipal budget. ${ }^{14}$ It is a process that provides democratic deliberation encouraging ordinary people to decide how to allocate an imaginary budget towards project(s). This process allows citizens to identify, contemplate, engage issues and ultimately prioritize public 

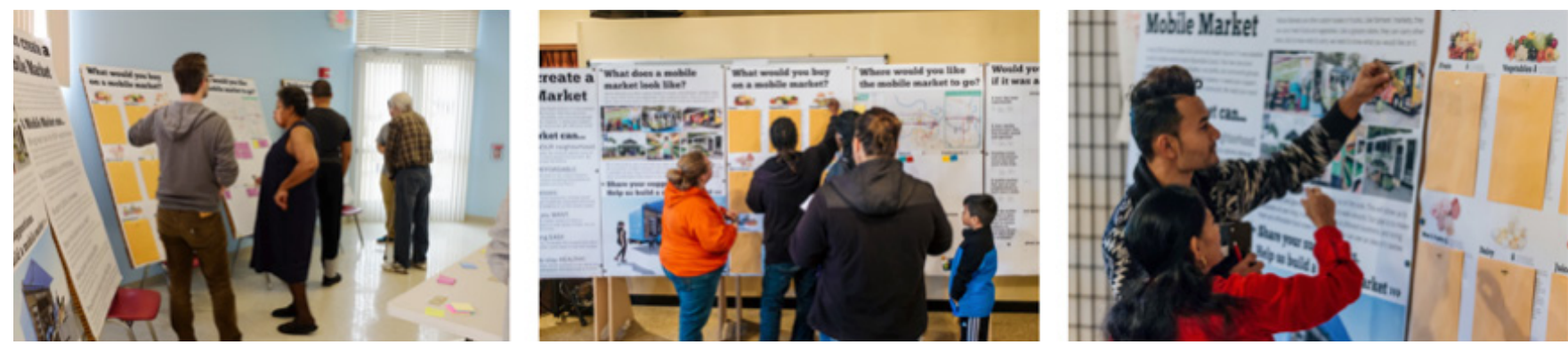

Students collect information from community partners through the Participatory Budgeting Method.
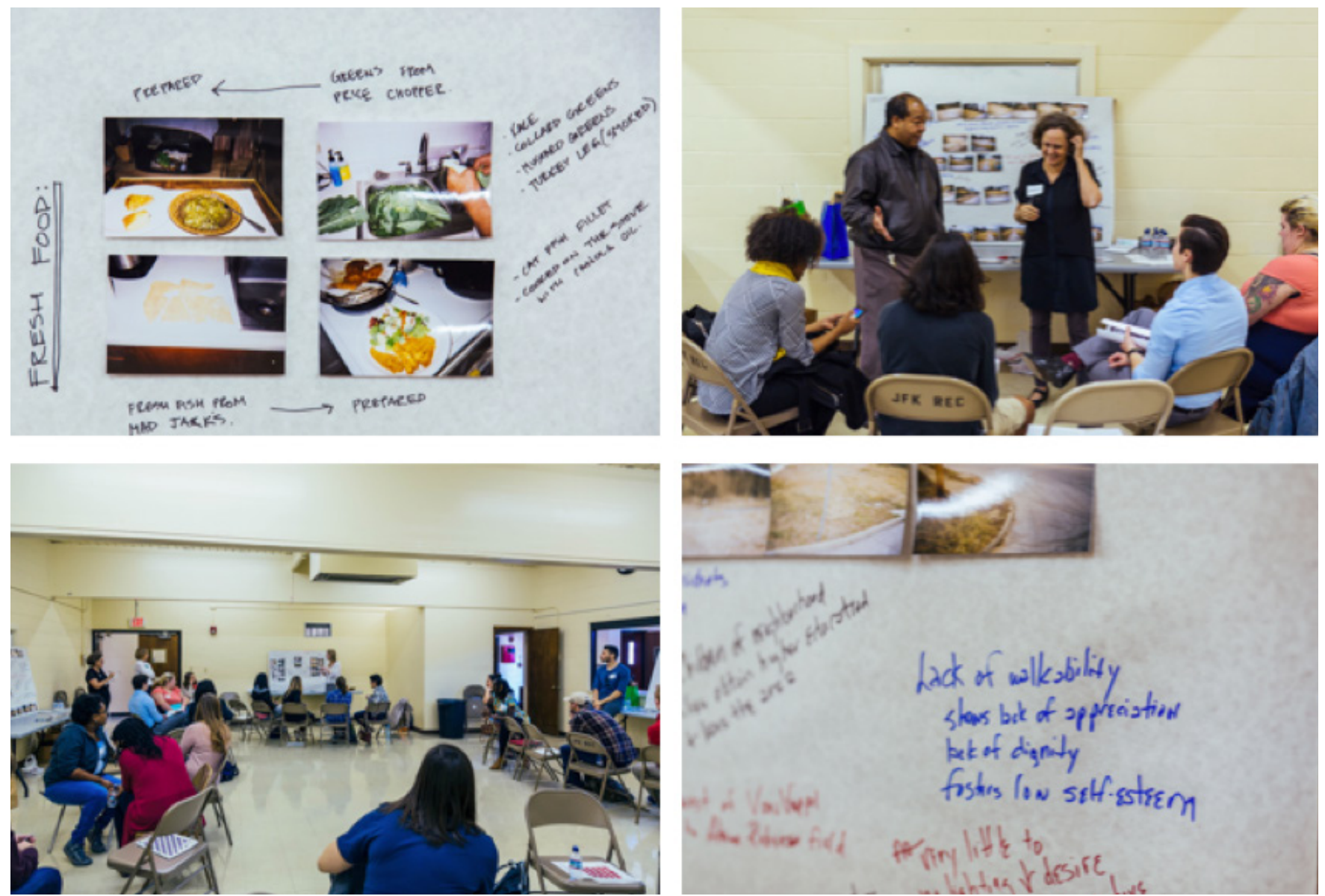

Students meet community members to discuss the Photovoice project.

spending. The process provides each participant the power to make decisions about how money is spent in contrast to the standard process where citizens don't have the opportunity to contemplate such tasks. This process allows citizens to deliberate and prioritize, revealing their individual values. The process is democratic and encourages citizenship learning. By playing out this process, even just as an exercise, it transforms the discussion by getting citizens to directly be involved in budgeting and giving them the tools to engage in decision-making power. It has the potential to empower individuals, build stronger civic discourse and raise public concerns and needs that a top-down approaches cannot see. The process encourages debates about the equitable

distribution of resources and insight about what priorities to consider from alternative viewpoints.

Photovoice, a participatory research methodology first formally articulated by Caroline Wang and Mary Anne Burris in 1997 , is a process by which individuals can identify, represent and enhance their perceptions of their community through a specific photographic technique. Individuals are prompted to capture visual representations of their everyday lives to share with others to gain insight into previously invisible practices, helping citizens to better engage in critical dialogue around the problems and opportunities it faces. As a method that is based in the production of knowledge it can enable people 
to photo-record and reflect their community's strengths and challenges and it can promote critical dialogue and knowledge about significant issues through group discussion of the photographs. ${ }^{15}$ This method is most useful when employed at the front-end of a project, during the evaluation and analysis stage. Like many creative methods, participants are more likely to engage in a study of their personal lives, where they are able to interpret their understanding of place and associations to others, rather than a traditional behavioral survey. ${ }^{16}$ Such creative work can lead to unique discoveries about others, their own behaviors and reveal priorities. To synthesize the findings from the collection of photos, it is common to have the participant explain the photos in a sorting method or collage of images in a particular order. Most often, patterns and themes emerge through the inventory of several photos from multiple participants, providing new insight.

This approach is a collaborative one in which agents act with, and on behalf of, others. Our inquiries as students and academics allow us into spaces where we are perceived as non-predatory, and can establish these spaces of exchange. In these spaces students learn to challenge their preconceptions as they sit at the table with citizen experts, made highly visible and forced into open dialogue, in real conversations where jargon is awkward. This participatory approach to making requires an indeterminate approach, where we learn by doing, working face-to-face, where all participants are driving our approach to the production of space and form. Students and community members find confidence in the roles they can play in the production of doing. They learn from each other, becoming active producers of space working with local needs, capacities and potential capabilities to transfer the work in direct ways.

\section{CONCLUSION}

As the work has proceeded to evolve, it has become apparent that our critical processes and findings are most useful when made visible and available to all involved: students, residents, stakeholders, leaders and policy makers, so that everyone recognizes their own abilities to contribute capacity and commitment in a collective project. This work generates a "joint commitment" where each participant makes a contribution to the collective body of understanding. It has transformed the student 'classroom' experience.

Through iterative, engagement events, participation in community shapes advocacy and civic discourse to gain multiple perspectives on what spaces add value and spaces that are having greatest impact (good and bad). Through an iterative process, the direction becomes self evident, discerning what public spaces have the potential for the greatest public impact, rallying the most interest and support to engage volunteers and civic support for future use. This layered and long process has made it possible to identify the projects that gain local interest and political buy-in to have the greatest impact--when it works best, it moves across tribal boundaries, connecting various neighborhoods for the common good. Data comes alive and available visually through the maps; data highlights the social and economic determinants of health; and ultimately, there is power in a shared idea that is compelling enough to set the direction in the work. Engaged design harnesses new energy and broadens the spatial agency of the future architect, the Citizen Architect.

\section{ENDNOTES}

1 Brown, Tim. Change by Design: How Design Thinking Transforms Organizations and Inspires Innovation. Harper Collins Publishers, USA, 2009.

2 Ibid.

3 Ibid.

4 Norris, D., and Baek, N. (2016). H.E.A.T. Healthy Equity Action Transformation. Report on Structural Issues Surrounding County Health Rankings in Wyandotte County, KS issued by the Kirwan Institute for the Study of Race and Ethnicity at The Ohio State University.

5 Ibid.

6 Ibid. "Home Owner's Loan Corporation (HOLC)'s chief purpose was to insure the refinance loans that lenders made to families desperate to keep their home. To safeguard the taxpayer money used to insure these loans, HOLC initiated a neighborhood assessment process in 239 American cities, Including Kansas City, MO/KS, to determine the relative risk of lending to residents in different sections of the city. HOLC engaged local realtors, mortgage lenders and others familiar with real estate landscape in their city to assess city neighborhoods for the risk that their residents might default on a home loan. HOLC standardized the assessment process by providing area-description forms, requiring assessors to evaluate neighborhoods and rate them $A, B, C$ or $D$ in increasing order of their insurance risk. Maps were drawn up reflecting these neighborhood risk ratings, with neighborhoods color-coded green ( $A$, "First Grade", "Best"), blue (B, "Second Grade", "Still Desirable"), yellow (C, "Third Grade", Declining") or red (D, "Fourth Grade", "Hazardous"). The highest risk, D-rated neighborhoods were considered "redlined" for home loans," 42.

7 Ibid.

8 Spatial Agency, 29

9 Ibid, 30

10 Ibid.

11 Rosa, Marcos and Ute Weiland (editors). Handmade Urbanism: From Community Initiatives to Participatory Models.

12 Henri Lefebvre, The Production of Space (Oxford: Blackwell, 1991), 81.

13 Martin, Bella and Bruce Hanington. Universal Methods of Design. Rockport Publishers, Beverly, MA, 2012.

14 Samuels, David. "From Socialism to Social Democracy: Party Organization and the Transformation of the Workers' Party in Brazil." Comparative Political Studies, p.3.

15 Wang C, Burris M: Empowerment through Photo Novella: Portraits of Participation. Health Educ Q 21(2):171-186, 1994.

16 Martin, Bella and Bruce Hanington. Universal Methods of Design. Rockport Publishers, Beverly, MA, 2012. 